\title{
PENGARUH YOGA ANTENATAL TERHADAP TINGKAT KECEMASAN PADA IBU HAMIL TW III DALAM MENGHADAPI PROSES PERSALINAN DI KLINIK YAYASAN BUMI SEHAT
}

\author{
Ni Gusti Ayu Pramita Aswitami \\ Sekolah Tinggi Ilmu Kesehatan Bina Usada Bali \\ Email: tami_chant@yahoo.com
}

\begin{abstract}
ABSTRAK
Kecemasan dalam menghadapi proses persalinan dapat terjadi pada masa kehamilan yang dapat menyebabkan syok, perdarahan dan berujung pada kematian. Adanya pelayanan kesehatan yang optimal, diharapkan dapat mengurangi tingkat kecemasan ibu hamil dalam menghadapi proses persalinan. Berdasarkan studi pendahuluan di Klinik Yayasan Bumi Sehat, terlihat dari 10 orang ibu hamil, terdapat 7 orang mengalami kecemasan dalam menghadapi proses persalinan dan 3 orang tidak mengalami kecemasan dalam menghadapi proses persalinan. Kecemasan pada ibu hamil terjadi karena ibu banyak mendengar cerita yang mengatakan melahirkan itu menyakitkan dan juga karena trauma ibu dengan persalinan yang lalu. Yoga antenatal merupakan salah satu cara yang dapat dilakukan oleh ibu hamil untuk mengurangi kecemasan dalam menghadapi proses persalinan. Tujuan penelitian ini adalah untuk mengetahui pengaruh yoga antenatal terhadap tingkat kecemasan dalam menghadapi proses persalinan.Pada penelitian ini menggunakan desain pre eksperimental dengan rancangan One-Group Pretest-Posttest design. Penelitian ini dilaksanakan di Klinik Yayasan Bumi Sehat, pada bulan Agustus-September 2016. Analisis data menggunakan uji statistik Wilcoxon Match Pairs Test.Hasil penelitian menggunakan uji statistik Wilcoxon Match Pair diperoleh p value sebesar 0,000 lebih kecil dari $\alpha$ 0,05 maka H0 ditolak atau hipotesis dalam penelitian ini diterima yaitu ada pengaruh pemberian yoga antenatal terhadap tingkat kecemasan pada ibu hamil TW III dalam menghadapi proses persalinan. Yoga antenatal yang diberikan pada ibu hamil memiliki pengaruh yang cukup signifikan untuk mengurangi kecemasan dalam menghadapi proses persalinan.
\end{abstract}

Kata Kunci : yoga antenatal, tingkat kecemasan, ibu hamil

\begin{abstract}
Anxiety in the labor process can occur during pregnancy which can cause shock, bleeding and lead to death. The existence of optimal health services, is expected to reduce the level of anxiety pregnant women in the process of childbirth. Based on preliminary studies in Clinical Yayasan Bumi Sehat, that of 10 pregnant women 7 women experience anxiety in labor and three people who did not experience anxiety in the face of labor, because the mother heard many stories - stories of the others say giving birth is painful and there mothers also traumatized by childbirth lalu.salah a way that can be done by pregnant women to reduce anxiety in the face of the delivery process is to conduct antenatal yoga. The purpose of this study was to determine the effect of antenatal yoga with the level of anxiety in the face of the delivery process. This study design is a pre-experimental research design with the design of the One-group pretest-posttest design. This research was conducted at the Yayasan Bumi Sehat Clinic, in August-September 2016. Data were analyzed using statistical tests Wilcoxon Match Pairs Test. The results using statistical test of Wilcoxon Match Pair obtained p value of 0.000 is smaller than $\alpha 0.05$ then Ho is rejected or accepted the hypothesis in this study that there is the effect of antenatal yoga with anxiety levels in pregnant women TW III facing the birth process. Yoga antenatal given to pregnant women to have a significant effect on reducing anxiety in the face of the delivery process. The results of this research is also expected to be further developed by other research
\end{abstract}

Keyword: Antenatal Yoga, Level Anxiety, Pregnancy 


\section{PENDAHULUAN}

Kebugaran tubuh sangat penting bagi wanita yang sedang hamil. Latihan pada saat hamil dianjurkan dilakukan setiap hari dengan tujuan untuk kebugaran, dan memperlancar proses persalinan. Pada umumnya, usia kehamilan seorang wanita terbagi menjadi 3 semester atau lebih dikenal dengan sebutan trisemester. Selama trisemester kehamilan, ibu mengalami perubahan fisik dan psikis yang terjadi akibat perubahan hormon. Perubahan ini akan mempermudah janin untuk tumbuh dan berkembang sampai saat dilahirkan.

Pada trimester ketiga (28-40 minggu) ibu hamil akan mengalami kecemasan menjelang persalinan terutama pada primigravida. Pada usia kandungan tujuh bulan keatas, tingkat kecemasan ibu hamil semakin berat dan sering, seiring dengan mendekatnya waktu kelahiran bayi. Disamping hal tersebut, pada masa trimester ini merupakan masa riskan terjadinya kelahiran bayi premature dan menyebabkan tingginya kecemasan pada ibu hamil.

Hormon yang dihasilkan selama kehamilan juga menyebabkan ligament yang mendukung sendi menjadi rileks. Hal ini membuat sendi mengalami pergerakan yang lebih banyak dan lebih beresiko mengalami cidera. Selama kehamilan, berat badan akan tertumpu kedepan atau lebih berat pada bagian depan, sehingga menggeser pusat dari gravitasi dan pusat stres. Kedudukan dari sendi dan otot terutama pada panggul dan punggung bagian bawah, sehingga dapat membuat ibu hamil menjadi kurang stabil dan kehilangan keseimbangannya terutama pada kehamilan lanjut, hal ini dapat mengakibatkan sakit pada punggung. Olahraga merupakan latihan yang aman dilakukan selama kehamilan untuk mengatasi ketidaknyamanan pada ibu, salah satunya sakit pada punggung dan pinggang.

Hobel dalam Jameson, (2002) menyatakan bahwa stres dapat menimbulkan beberapa reaksi dalam tubuh ibu hamil. Kecemasan yang terjadi terus menerus dapat menyebabkan saraf simpatis memacu kerja pernafasan paru-paru guna mengalirkan oksigen ke jantung, sehingga jantung dengan kuat memompa darah guna dialirkan keseluruh tubuh, termasuk yang dialirkan kedalam janin melalui plasenta dalam rahim ibu. Kondisi ini berarti menekan janin dengan kuat, akibatnya janin tergoncang seolah-olah didesak untuk keluar dari rahim, yang dapat menyebabkan kelahiran bayi premature (Dariyo, 1997).

Salah satu olahraga yang aman selama kehamilan adalah yoga antenatal. Secara etimologis, kata yoga diturunkan dari kata yuj (Sansekerta), yoke (Inggris), yang berarti 'penyatuan' (union). Yoga berarti penyatuan kesadaran manusia dengan sesuatu yang lebih luhur, transenden, lebih kekal dan ilahi.

Menurut Panini yoga diturunkan dari akar sansekerta yuj yang memiliki tiga arti yang berbeda, yakni: penyerapan, Samadhi (yujyate) menghubungkan (yunakti), dan pengendalian (yojyanti). Namun makna kunci yang biasa dipakai adalah 'meditasi' (dhyana) dan penyatuan (yukti).

Yoga adalah sebuah ilmu pengetahuan kuno yang berakar dari filosofi Hindu dan bersifat pantheisme (kepercayaan bahwa seluruh alam semesta dan isinya bersifat ilahi). Ilmu ini sangat kompleks dan membicarakan banyak aspek dari manusia, mulai dari tataran fisikal hingga ke tataran spiritual. Yoga menciptakan keseimbangan antara emosional, mental, fisik dan dimensi spiritual. Yoga merupakan suatu sistem yang komprehensif antara fisik (asana), latihan pernafasan (pranayama), konsentrasi dan meditasi (dharana dan dhyana) dan kontemplatif praktek.

Senam yoga adalah jenis olahraga tubuh, pikiran dan mental yang sangat membantu ibu hamil melenturkan persendian, termasuk menenangkan pikiran. Seni yang telah lama berkembang sejak ribuan tahun yang berasal dari India ini, sebagai suatu bentuk penghargaan terhadap janin dan proses terjadinya kehamilan.

Senam yoga merupakan program olahraga ringan dimana latihannya menggabungkan prinsip-prinsip yoga. Yoga merupakan pendekatan secara holistic berupa fisik, mental dan spiritual (Biljani, 2008) yang melibatkan kombinasi peregangan otot tubuh, meditasi pernafasan, dan mendorong pertumbuhan kesehatan dan spiritual bila melakukannya.

Gerakan prenatal yoga dirancang khusus untuk melatih otot-otot rahim agar bisa menunjang ruang gerak janin di dalam kandungan. Dengan begitu, janin bisa berkembang dan bergerak secara optimal. Yoga juga membuat calon ibu lebih releks, dan kondisi ini baik untuk janin. Saat melakukan yoga seorang ibu harus merasa 
senang dan tidak stress, karena dapat merugikan ibu dan mengganggu pertumbuhan janin.

Yoga bertujuan melatih otot panggul dan sekitarnya, agar menjadi lebih kuat dan elastis. Sirkulasi darah disekitar daerah panggul menjadi lebih lancar sehingga memudahkan ibu melakukan persalinan secara normal. Dengan latihan pernafasan yang dilakukan selama yoga, ibu akan terbiasa melakukan nafas pendek dan cepat dengan ritme yang teratur serta panjang dan dalam baik saat menghirup maupun melepaskan udara. Pelatihan nafas bisa menenangkan calon ibu untuk melalui rasa sakit dalam proses persalinan, serta memicu sistem saraf yang memperlancar pembukaan dan peregangan dinding vagina.

Prenatal yoga dapat dilakukan setiap hari selama 1-1,5 jam. Sementara bagi ibu yang bekerja, dapat melakukan gerakan di pusat yoga atau dirumah dengan ditemani suami. Jika rutin dilakukan, otot-otot perut semakin kuat, tubuh lebih elastis, keluhan nyeri, serta beban perut yang semakin besar tidak akan mengganggu ibu hamil saat beraktifitas. Dapat dilakukan sepanjang kehamilan. Selama tak ada peregangan otot perut, yoga sangat bermanfaat untuk membantu ibu hamil lebih santai.

\section{METODE}

Penelitian ini menggunakan pre eksperimental dengan desain penelitian OneGroup Pretest-Postest design yaitu suatu penelitian pre eksperimental di mana peneliti memberikan perlakuan pada kelompok studi tetapi sebelumnya diukur atau ditest (pretest) selanjutnya setelah perlakuan kelompok studi diukur atau ditest kembali (posttest) (Budiman, 2011).

Jumlah subjek penelitian yang diperoleh adalah 35 orang ibu hamil TW III. Sebelum diberi perlakuan subjek diberikan kuisioner yang bertujuan untuk mengetahui tingkat kecemasan. Kuisioner yang diberikan adalah kuisioner Hamilton Anxiety Rating Scale (HARS) setelah kuesioner diisi maka dihitung hasilnya. Kemudian subjek diberikan perlakuan yaitu yoga selama 3 minggu dengan durasi 2 kali dalam seminggu. Setelah 3 minggu maka subjek diberikan kuisioner kembali untuk mengetahui tingkat kecemasannya.

Penelitian dilakukan pada bulan Agustus - September 2016 di Yayasan Bumi Sehat. Rancangan analisis dalam penelitian ini adalah analisis univariat dan bivariat untuk menganalisis hubungan antara variabel bebas dan variabel terikat.

\section{HASIL DAN PEMBAHASAN}

Penelitian ini dilaksanakan pada bulan Agustus-September 2016. Subjek penelitian yang terlibat sejumlah 35 orang ibu hamil TW III. Penelitian ini dilaksanakan di Yayasan Bumi Sehat. Analisis univariat yang dilakukan untuk mengetahui tingkat kecemasan ibu hamil sebelum dilakukan yoga adalah sebagai berikut:

Tabel 1. Tingkat Kecemasan Responden Sebelum Diberikan Yoga Antenatal

\begin{tabular}{lll}
\hline Tingkat kecemasan & Frekuensi (f) & Persentase $(\%)$ \\
\hline Tidak cemas & 2 & 5,8 \\
Cemas ringan & 8 & 22,8 \\
Cemas sedang & 9 & 25,7 \\
Cemas berat & 16 & 45,7 \\
Panik & 0 & 0 \\
Total & 35 & 100,0 \\
\hline
\end{tabular}

Berdasarkan Tabel 1 terlihat bahwa terdapat sebagian besar ibu memiliki kecemasan berat yaitu sebesar $45,7 \%$ sebelum diberikan yoga antenatal.

Analisis univariat dilakukan untuk mengetahui tingkat kecemasan ibu hamil setelah diberikan yoga antenatal. Berdasarkan Tabel 2 terlihat bahwa terdapat sebagian besar ibu memiliki kecemasan ringan yaitu sebesar $40,0 \%$ setelah diberikan yoga antenatal. 
Tabel 2. Tingkat kecemasan Responden Setelah Diberikan Yoga Antenatal

\begin{tabular}{lll}
\hline Tingkat kecemasan & Frekuensi (f) & Persentase $(\%)$ \\
\hline Tidak cemas & 9 & 25,7 \\
Cemas ringan & 14 & 40,0 \\
Cemas sedang & 3 & 8,6 \\
Cemas berat & 9 & 25,7 \\
Panik & 0 & 0,0 \\
Total & 35 & 100,0 \\
\hline
\end{tabular}

Analisis berikutnya adalah analisis untuk mengukur perbedaan tingkat kecemasan sebelum dan sesudah diberikan yoga antenatal. Berdasarkan Tabel 3 dengan menggunakan uji statistic Wilcoxon Match Pair diperoleh $\mathrm{p}$ value sebesar 0,000 lebih kecil dari $\alpha$ 0,05 maka H0 ditolak atau hipotesis dalam penelitian ini diterima yaitu ada pengaruh pemberian yoga antenatal dengan tingkat kecemasan pada ibu hamil TW III dalam menghadapi proses persalinan.

Tabel 3. Perbedaan Tingkat Kecemasan Responden Sebelum dan Sesudah Diberikan Yoga Antenatal

\begin{tabular}{llll}
\hline Katagori & $\begin{array}{l}\text { Tingkat Kecemasan } \\
\text { Sebelum Diberikan } \\
\text { Yoga antenatal }\end{array}$ & $\begin{array}{l}\text { Tingkat } \\
\text { Kecemasan } \\
\text { Sesudah }\end{array}$ & Pre-Post \\
& & $\begin{array}{l}\text { Diberikan } \\
\text { Yoga antenatal }\end{array}$ & \\
\hline Tidak cemas & 2 & 9 & \\
Cemas ringan & 8 & 14 & \\
Cemas sedang & 9 & 3 & \\
Cemas berat & 16 & 9 & \\
Panik & 0 & 0 & $-5,659$ \\
Z & & & 0,000 \\
Sig & & & \\
\hline
\end{tabular}

Kecemasan ibu hamil dapat muncul karena masa panjang saat menanti kelahiran penuh ketidakpastian. Selain itu bayangan tentang hal-hal yang menakutkan saat proses persalinan walaupun apa yang dibayangkannya belum tentu terjadi. Situasi ini menimbulkan perubahan drastis, bukan hanya fisik tetapi juga psikologis.

Kecemasan adalah suatu pengalaman subjektif mengenai ketegangan mental yang menggelisahkan sebagai reaksi umum dan ketidakmampuan menghadapi masalah atau adanya rasa aman. Perasaan kecemasan ini umumnya menimbulkan gejala-gejala fisiologis dan gejala-gejala psikologis. Dengan makin tuanya kehamilan, maka perhatian dan pikiran ibu hamil mulai tertuju pada sesuatu yang dianggap klimaks, sehingga kecemasan yang dialami ibu hamil akan semakin intensif saat menjelang persalinan. Upaya untuk bisa dilakukan dalam mengurangi tingkat kecemasan dan mempersiapkan ibu dalam menghadapi persalinan yaitu melalui yoga atau latihan senam hamil.
Analisis pengaruh yoga antenatal dengan tingkat kecemasan pada ibu hamil TW III dalam menghadapi proses persalinan dalam penelitian ini didapatkan bahwa dari 35 responden didapatkan bahwa dari hasil uji statistik menggunakan Wilcoxon Match Pairs Test didapatkan nilai $p$ value sebesar 0,000 lebih kecil dari $\alpha \quad 0,05$ maka H0 ditolak atau hipotesis dalam penelitian ini diterima yaitu ada pengaruh pemberian yoga antenatal dengan tingkat kecemasan pada ibu hamil TW III dalam menghadapi proses persalinan.

Yoga antenatal adalah sebuah ilmu yang menjelaskan kaitan antara fisik, mental, dan spiritual manusia untuk mencapai kesehatan yang menyeluruh (Sindhu, 2009). Melakukan latihan yoga pada saat hamil, akan mempersiapkan tubuh maupun pikiran untuk siap dan tegar menghadapi masa persalinan (Wiadnyana, 2011). Manfaat yoga antenatal dikatakan memudahkan proses persalinan, mengurangi kecemasan dan mempersiapkan mental sang ibu untuk menghadapi persalinan, melancarkan sirkulasi darah dan asupan oksigen ke janin, 
menjalin komunikasi antara ibu dan anak sejak masih berada di dalam kandungan, mempercepat pemulihan fisik dan mengatasi depresi pasca melahirkan, meningkatkan kekuatan dan stamina tubuh saat hamil.

Kecemasan seseorang dipengaruhi oleh banyak hal, selain yoga antenatal, yang paling terpenting dalam menurunkan kecemasan adalah dukungan keluarga khususnya suami. Faktor yang dapat mengurangi kecemasan yang terjadi pada wanita yang akan melahirkan adalah adanya dukungan keluarga yang dapat berupa dari suami, keluarga atau saudara lainnya, orang tua, dan mertua.

Menurut Suriany (2009), manfaat melakukan prenatal yoga bisa membantu memudahkan persalinan. Yoga melatih otototot tubuh yang disertai cara olah nafas. Melalui gerakan tubuh yang disertai teknik pengaturan nafas dan pemusatan konsentrasi, fisik akan lebih sehat, bugar, kuat dan emosi akan lebih seimbang. Yoga juga bermanfaat untuk mencegah dan pengelolaan penyakit kronis yang beraitan dengan gaya hidup. Yoga yang dilakukan selama kehamilan akan mengurangi terjadinya komplikasi.

\section{KESIMPULAN}

Berdasarkan hasil penelitian dengan menggunakan uji statistik diperoleh nilai $\mathrm{p}$ value sebesar 0,000 lebih kecil dari $\alpha 0,05$ yang artinya terdapat pengaruh yoga antenatal terhadap tingkat kecemasan pada ibu hamil TW III dalam menghadapi proses persalinan. Disarankan kepada ibu hamil agar dapat melakukan yoga antenatal secara rutin sehingga mampu memberikan dampak pengurangan kecemasan dalam menghadapi proses persalinan.

\section{DAFTAR PUSTAKA}

Artal, R. M. OT. (2003). Guidelines of the American College of Obstetricians and Gynecologists for exercise during pregnancy and postpartum period. $\mathrm{Br}$ J Sports Med. 37(6).

Bayu, I. D. (2013). Asuhan Kehamilan Berbasis Bukti Paradigma Baru Dalam Asuhan Kebidanan. Jakarta: Sagung Seto.

Bredin, SSD. F.H, Burr, J. F, Charlesworth S. H. (2005). Risk assessment for physical activity and exercise clearance in pregnant women without contraindications. Canadian Family Physician 59 (7).

Mottola, M. F. M. R. (2011). Exercise and Pregnancy: Canadian Guiddelines for Health Care Professionals. Edmonto: Alberta Centre for Active Living.

Devi Asmirani. (2011). Yoga Untuk Semua. Jakarta: Gramedia.

Shindu P. (2009). Yoga Untuk Kehamilan. Sehat, Bahagia \& Penuh Makna. Bandung.

Paul Sorace (2010). Guidelines for Exercise Training during Pregnancy: AFPA Teaching Faculty.

Budiman. (2011). Penelitian Kesehatan. Bandung : PT Refika Aditama.

Saryono, A. (2010). Metodologi Penelitian Kebidanan DIII, D IV, S1 dan S2. Jakarta : Nuvia Medika.

Wiadnyana. (2011). Panduan Praktis Yoga pada Masa Kehamilan dan Pascapersalinan. Jakarta : PT Gramedia Widiasarana. 